\title{
UM OLHAR QUEER SOBRE A EDUCAÇÃO SEXUAL
}

\author{
Érick Roberto Freire de Araújo Silva ${ }^{1}$; Fátima Elisabeth Denari²
}

\section{A QUEER VIEW ABOUT SEX EDUCATION}

Resumo: A educação sexual compreende uma variável fundamental para o desenvolvimento crítico e para a emancipação política e social dos/as educandos/as. Contudo, ela não ocorre de forma efetiva. A relutância do poder legislativo e a omissão do executivo, subalternizados pelo conservadorismo, têm responsabilidade central para a manutenção desse cenário. Desse modo, haja vista que a educação formal é um espaço estratégico para o trabalho com temas voltados para a sexualidade, as ações nesse ambiente devem ser incentivadas e garantidas pelo poder público. Este trabalho buscou produzir um panorama das características da teoria queer que convergem com os preceitos da educação sexual, inclusive a escolar. Todo esse enredo buscou desvelar a possibilidade de uma pedagogia queer, que pode potencializar a educação sexual no espaço escolar.

Palavras-chave: teoria queer, educação sexual

Abstract: Sex education at school comprises a variable key for the critical development and political and social emancipation for the students. However, in fact, it is not effective. The reluctance of the legislative and the omission of the executive, subordinated by conservatism, have primary responsibility for the maintenance of that condition. Considering the formal education has a strategic role of working with themes related to sexuality, some actions in that area should be encouraged and guaranteed by the Government. This research aimed to produce a panorama of the features of the queer theory that converge with the precepts of sexual education, including educational. This entire plot sought to reveal the possibility of a queer pedagogy, which can enhance sex education at school.

Keywords: queer theory; sex education

\footnotetext{
${ }^{1}$ Mestre em Educação Sexual, pela Universidade Estadual Paulista (2016). Licenciado em Ciências Exatas, com habilitação em Matemática e em Ciências Físicas e Biológicas, pela Universidade de São Paulo (2010). Professor de Educação Básica na Escola Municipal de Sertãozinho Prefeita Maria Neli Mussa Tonielo. E-mail: erick.usp@gmail.com

2Doutora em Metodologia do Ensino pela Universidade Federal de São Carlos (1997). Mestre em Educação Especial pela Universidade Federal de São Carlos (1984). Graduada em Estudos Sociais pela Associação de Escolas Reunidas de São Carlos (1976). Graduação em Complementação Pedagógica pela Faculdade São Luiz (1986). Professora associada junto ao Departamento de Psicologia da Universidade Federal de São Carlos. Professora colaboradora junto ao Programa de Pós-Graduação em Educação Sexual da Universidade Estadual Paulista. Tem experiência na área da psicologia, com ênfase no desenvolvimento humano. E-mail: fadenari@terra.com.br
} 


\section{Introdução}

A sexualidade tomou corpo como arte e ciência conforme tornou-se objeto de estudo de cientistas, religiosos, educadores, curiosos, e outros mais que se aventuraram ao estudo e às descobertas da área. Constituiu-se nos últimos dois séculos por meio de muitos olhares e perspectivas, apesar de, em tese, sempre existir. Não obstante ter sido descrita, apreendida, detalhada, dividida e categorizada, vem perdendo contato com sua essência, na medida em que contempla o efêmero, o inconstante, o estranho e o incompreensível.

É certo que tem sido alvo de controle e regulação, desde que é possível contar. Os diversos governos e as instituições, como a igreja e a própria família, têm verdades sobre esse conceito que devem ser difundidas por seus agentes. Algumas dessas verdades se complementam. Muitas outras se contradizem. Mas não deixam de ser verdades, pois normatizam a relação da sociedade com a sexualidade.

Este trabalho busca produzir um panorama mostrando os possíveis pontos de contato entre a teoria queer e a educação sexual, inclusive a escolar. Para isso, foram traçadas algumas características dessa área de conhecimento que convergem em uma forma fluida denominada teoria queer, passando por seus pressupostos e influências, bem como por seus teóricos. Todo esse enredo busca desvelar a possibilidade de uma pedagogia queer, que pode influenciar a educação sexual. $\mathrm{O}$ autor se respaldou em estudos de Louro (2013), Miskolci (2010), Butler (2010), Salih (2013), Silva (2005), entre outros.

\section{A teoria queer na pós-modernidade}

A teoria queer não pode ser definida ou apreendida. Não pode ser reproduzida ou exercitada. Não pode ser exemplificada. Nem ao menos pode ser compreendida dentro das fronteiras de uma teoria. A imobilidade de uma definição elimina a essência queer.

Podemos nos debruçar sobre ensaios e densas leituras. Mas experimentar a teoria queer só será possível por meio de uma determinada relação estabelecida entre sua a mente e o objeto de estudo. Com uma perspectiva libertária e emancipatória e com um pensar crítico, é possível vislumbrá-la. Porém, ao mesmo tempo em que buscamos compreendê-la em seu todo, perdemos a epifania. Se a dominamos, não se trata da teoria queer.

Como afirma Louro (2013, p. 7), queer é estranho, esquisito, excêntrico. É o sujeito da sexualidade desviante, que não almeja ser integrado tampouco tolerado. Trata-se de um jeito de pensar que desafia as normas regulatórias da sociedade. "Queer é um corpo estranho que incomoda, perturba, provoca e fascina".

O termo "queer" trata da apropriação de um discurso utilizado como insulto e ofensa e sua essência reside, justamente, no fato de não ser passível de definição exata. "O queer é um momento, um movimento, um motivo contínuo - recorrente, vertiginoso, troublant [perturbador]" (SEEDGWICK, 1994, p. 12). Ainda de acordo com Seedgwick, uma influente teórica queer, a raiz latina da palavra significa "atravessado", que vem da raiz indo-latina torquere, de "torcer", e da inglesa athwart de "través". Mas, como já tratado, os teóricos convergem em não atribuir uma definição limitada da expressão.

A teoria queer está sendo difundida, naturalmente, na pós-modernidade, quando é necessário pensar, não só em processos mais confusos, difusos e plurais, mas especialmente supor o sujeito como fragmentado, fluido e cambiante (LOURO, 2013).

Contrariamente às teorias sociais, que buscam apresentar resultados e explicitar fenômenos, a teoria queer questiona as normas e a própria forma de pensar a cultura, sem que para isso, necessariamente, precise apresentar uma alternativa ou solução aplicável. Após o contato com a teoria queer, tem-se apenas muito mais conflitos e dúvidas. No entanto, desenvolve o sujeito, subvertendo-o.

\section{Os pensadores queers}

Seus principais teóricos possuem uma obra muito diversificada. Por volta dos anos 1990, seus pressupostos podiam sem percebidos claramente na perspectiva teórica de um grupo diverso de autores, que convergiam em alguns aspectos.

Os/as teóricos/as queer constituem um agrupamento diverso que mostra importantes desacordos e divergências. Não obstante, eles/elas compartilham alguns 
compromissos amplos - em particular, apoiar-se fortemente na teoria pós-estruturalista francesa e na desconstrução como um método crítica literária e social; põem-se em ação, de forma decisiva, categorias e perspectivas psicanalíticas; são favoráveis a uma estratégia descentradora ou desconstrutiva que escapa das proposições sociais e políticas programáticas positivas; imaginam o social como um texto a ser interpretado e criticado com o propósito de contestar os conhecimentos e as hierarquias sociais dominantes. (SEIDMAN, 1995, p. 125).

Apesar de não entrar diretamente em conflito com teorias afins, a teoria queer propõe um entendimento fundamental que diverge. Assim mostra Salih (2013, p. 20):

Enquanto os estudos de gênero, os estudos gays e lésbicos e a teoria feminista podem ter tomado a existência de "o sujeito" (isto é, o sujeito gay o sujeito lésbico, a fêmea, o sujeito "feminino") como um pressuposto, a teoria queer empreende uma investigação e uma desconstrução dessas categorias, afirmando a indeterminação e a instabilidade de todas as identidades sexuais e generificadas.

A teoria queer estimula essa viagem de reconstrução do ser, negando o naturalizado. Nesse trajeto, de certo, "[...] há, aqui, formação e transformação, mas num processo que, ao invés de cumulativo e linear, caracteriza-se por constantes desvios e retornos sobre si mesmo, um processo que provoca desarranjos e desajustes, de modo tal que só o movimento é capaz de garantir algum equilíbrio ao viajante" (LOURO, 2013, p. 13).

A transgressão está presente não só na relação do sujeito com a sociedade, mas também na forma de perceber essa relação. Essa transgressão ocorre, por vezes, pelo movimento e pela fluidez da essência do gênero e da sexualidade. Mais do que o ponto de chegada, o subversivo encontra prazer no trajeto e nas nuanças do estar "entre mundos".

Usada como lente, a teoria queer permite enxergar processos até então despercebidos, ou pelo menos não questionados, como a regulação do gênero. $A$ identidade do ser $e$ do corpo é construída e estabelecida antes do nascimento, por agentes sociais. Muitas vezes de forma involuntária.

O descobrimento do sexo do bebê, geralmente por volta do quarto mês de gestação, inicia um protocolo de regulação complexo e sistemático. Sistemático porque a ordem precisará ser reiterada ao longo da vida. Esse processo determina no ser em desenvolvimento definições e uma direção a ser seguida. São decisões externas sobre a identidade pessoal daquele sujeito. De acordo com Judith Butler (1993), essa decisão desencadeia um processo de adequar esse corpo ao universo masculino ou feminino. Processo esse baseado em características físicas, categorizadas socialmente, às quais são atribuídas significados culturais.

De acordo com Louro (2013, p. 15):

$\mathrm{O}$ ato de nomear o corpo acontece no interior da lógica que supõe o sexo como um "dado" anterior à cultura e the atribui um caráter imutável, a-histórico e binário. Tal lógica implica que esse "dado" sexo vai determinar o gênero e induzir a uma única forma de desejo. Supostamente, não há outra possibilidade senão seguir a ordem prevista, A afirmação "é um menino" ou "é uma menina" inaugura um processo de masculinização ou de feminização com o qual o sujeito se compromete.

Assim, o sujeito nasce com uma carga de comprometimento e está, de certa forma, obrigado a viver segundo esses preceitos.

De acordo com Louro (2013, p. 16), apesar de tudo isso, o processo é subvertido. "Mesmo que existam regras, que se tracem planos e sejam criadas estratégias e técnicas, haverá aqueles e aquelas que rompem as regras e transgridem os arranjos".

A sexualidade, em especial, escapa ao controle, quase que instintivamente, e sempre há aqueles e aquelas que recusam "a instituição de uma heterossexualidade compulsória e naturalizada" (BUTLER, 2010, p. 46).

Nesse ponto, entra em campo a pedagogia corretiva, comprometida em fazer a manutenção das estruturas culturais vigentes. Muito bem articulada com instâncias e instituições contemporâneas, direciona sistematicamente e de forma arbitrária planos de recuperação para adequação. "Para eles e para elas a sociedade reservará penalidades, sanções, reformas e exclusões" (LOURO, 2013, p. 16). 
Os tidos como desviantes devem inscrever em seus corpos o gênero e a sexualidade pré-estabelecida com base nos corpos sexuados. Assim podem ser conduzidos de volta às margens de conforto da sociedade. Mas, de fato, não podem ser incluídos por essa perspectiva.

Há sim, sujeitos que caminham no sentido contrário, buscando uma afirmação e uma visibilidade para garantir direitos e serem tolerados e respeitados. Nesse caminho, distanciam-se do marco regulatório, que por sua vez torna-se mais persistente. "Paradoxalmente, ao se afastarem, fazem-se ainda mais presentes" (LOURO, 2013, p. 18).

Pouco se faz pela implantação de uma reforma completa buscando modificar a forma como o processo se estabelece. Um olhar queer não ignora a luta dos sujeitos transgressores, mas amplia o horizonte de suas demandas e almeja uma releitura da cultura e das estruturas sociais. Para que não se faça necessário o reconhecimento do desviante, por não ser mais imperativo estabelecer essa relação de "desvio", torna-se necessário discutir as formulações de normalidade. O próprio sujeito apresentado como legítimo e dentro da normalidade precisa desvelar dentro de si uma essência queer. 23),

Logo, e de acordo com Louro (2013, p.

[...] a visibilidade e a materialidade desses sujeitos parecem significativas por evidenciarem, mais do que os outros, o caráter inventado, cultural e instável de todas as identidades. São significativas, ainda, por sugerirem concreta e simbolicamente possibilidades de proliferação e multiplicidade das formas de gênero e de sexualidade.

Não pretendem, porém, tornarem-se referência para uma nova forma de identidade estática e reproduzível, que pouco contribuiria na busca de uma nova forma de pensar a cultura.

Em particular, os teóricos que mais contribuíram para a construção desse olhar se apoiaram na teoria pós-estruturalista. Mas os subsídios teóricos partiram de diversas áreas do conhecimento, permitindo uma interpretação coesa e articulada que norteia a teoria queer sem limitá-la.

Tiveram papéis fundamentais as proble- matizações: dos conceitos de sujeito - por Freud e suas formulações sobre "o inconsciente e a vida psíquica"; e dos processos de identificação e de agência - por Lacan e Althusser, que respectivamente, afirmam que "o sujeito nasce e cresce sob o olhar do outro" e que "os sujeitos são interpelados e capturados pela ideologia" (LOURO, 2013, p. 41).

Michel Foucault, com seus insights sobre sexualidade, e Jacques Derrida e seu procedimento teórico de desconstrução, embasam grande parte das pesquisas e procedimentos teóricos desvelados por meio da teoria queer.

Outra pensadora que se destaca com suas formulações sobre sexo, gênero e sexualidade é Judith Butler. Por muitos apontada como a rainha queer, Butler chama atenção para as normas regulatórias que norteiam posturas em relação ao sexo e a sexualidade. Em geral, apoiam-se na heteronormatividade compulsória e produzem efeito categorizador e segregacionista. De acordo com Butler, essas normas precisam ser reiteradas constantemente, já que os corpos não se conformam, nunca completamente, às normas pelas quais sua materialização é imposta (BUTLER, 1993). Assim, instituições regulatórias têm grande papel no reconhecimento dessas normas para que tenham efeito.

\section{Butler e a teoria Queer}

Tida por alguns como "the queer queen", Judith Butler, professora de retórica e literatura comparada na Universidade da Califórnia, em Berkeley, e emblemática pesquisadora feminista, procura não se limitar pelos rótulos a ela atribuídos. Talvez seja esse, justamente, um critério que a consagra como uma teórica queer.

Ao não se filiar a nenhuma escola de pensamento, Butler tem liberdade para perturbar a ordem e inquietar noções consagradas. Para além dos estudos gays e lésbicos, das teorias feministas e queer, Butler se debruça, a princípio, sobre a formação do sujeito e questões de identidade, mas transcende esses temas e tem atraído estudiosos de diversas áreas do conhecimento.

Mesmo o sujeito de que fala Butler não é um indivíduo, mas toda uma estrutura linguística em formação. Assim como o subversivo nem sempre condiz com o difundido pelos mais progressistas muitas vezes, por mais ex- 
cêntrico que possa ser, acaba por consolidar a política dominante. As relações de poder explícitas e naturalizadas têm papel marcante nessa distinção.

Em sua obra, recorre frequentemente às teorias pós-estruturalista e psicanalítica, assim como a feminista, porém obteve uma primeira notoriedade ao discutir a obra de Hegel e seu impacto sobre os filósofos franceses do século $X X$.

Sara Salih (2013, p. 10) se empenha na tarefa de sintetizar a importância dessa teórica:

De fato, se tivéssemos de "situar" Butler (uma tarefa que iria contra o espírito Butleriano, se é que existe tal coisa), suas teorizações sobre a identidade "generificadas" e sexuadas seriam vistas provavelmente como as suas mais importantes intervenções no variado conjunto dos campos acadêmicos com os quais está ligada. Seus livros mais conhecidos, Gender trouble (1990) e sua "sequência" Bodies that matter (1993), são encontrados em muitas listas de leitura sobre estudos de gênero e provavelmente são estudados por muitas pessoas que trabalham na área da teoria queer, da teoria feminista, da teoria gay e lésbica.

A obra de Butler não pode ser categorizada, ou mesmo podem ser listadas suas influências.

As teorias de Butler contemplam noções fundadas na dialética hegeliana, processo marcado por uma tese que é negada e contestada na forma de antítese resolvida, por sua vez, em uma síntese, que não necessariamente marca o fim do processo. Essa síntese serve de base para novas teses, e dessa forma o conhecimento é reestruturado. Tratando-se de Butler, a síntese de forma alguma representa uma verdade absoluta, e o processo de busca recebe destaque em relação à resolução final, que nunca é alcançada.

De fato, ela vê a resolução como perigosamente antidemocrática, pois ideias e teorias que se apresentam como "verdades" autoevidentes são, com frequência, veículos para pressupostos ideológicos que oprimem certos grupos sociais, particularmente as minorias ou grupos marginalizados (SALIH, 2013, p. 13).

Uma das bases da teoria queer, muito presente na obra de Butler, discute as categorias pelas quais os sujeitos são tratados, como marca mais expressiva de sua identidade. Investiga-se o processo de construção e a atribuição de sentido a esses termos generificadores, sugerindo a presença de modelos alternativos de tratamento das identidades. As produções têm buscado a desestabilização da categoria "sujeito", processo chamado por ela como uma genealogia crítica das ontologias de gênero (BUTLER, 2010). As relações de poder configuradas por meios das categorizações têm papel central nessa discussão.

Nesse ponto, Salih (2013, p. 16) conclui de forma representativa:

Butler não é uma freudiana ou uma foucaltiana, tampouco uma marxista, uma feminista ou uma pós-estruturalista; em vez disso, podemos dizer que ela tem afinidades com essas teorias e com seus projetos políticos, não se identificando com nenhuma delas em particular, mas utilizando uma série de paradigmas teóricos sempre que pareça conveniente, sob as mais variadas, e por vezes inesperadas, combinações.

Há muito não se pensa no "sexo" como essência biologicamente determinada e estável, mas disforme e com fluidez epistemológica.

Uma investigação genealógica da constituição do sujeito supõe que sexo e gênero são efeitos - e não causas - de instituições, discursos e práticas; em outras palavras, nós, como sujeitos, não criamos ou causamos as instituições, os discursos e a práticas, mas eles nos criam ou causam, ao determinar nosso sexo, nossa sexualidade, nosso gênero. As análises genealógicas de Butler vão se concentrar no modo como o efeito-sujeito, como ela o chama, se dá, e ela sugere, além disso, que há outros modos pelos quais o sujeito poderia se efetuar. (SALIH, 2013, p. 21)

Esse discurso vai ao encontro da famosa provocação de Beauvoir de que "ninguém nasce mulher: torna-se uma mulher" (1980, p. 9).

\section{A identidade e a educação sexual}

Nos dias de hoje, a vigilância sobre a se- 
xualidade prevalece, mas "agora se ampliaram e diversificaram suas formas de regulação, multiplicaram-se as instâncias e as instituições que se autorizam a ditar-lhe as normas" (LOURO, 2013, p. 27). Outros grupos reivindicam sobre o sexo sua ética e sua moral. A igreja se reinventa mas não suaviza seu discurso. Os governos se satisfazem buscando índices aceitáveis, sem promover uma discussão de fato. Mesmo os movimentos sociais se organizam desorganizadamente e promovem uma verdade alternativa sem reflexão.

Grupos marginalizados e oprimidos estão conquistando grande visibilidade e, por consequência, são mais facilmente hostilizados por frentes conservadoras. Esse eterno debate entre as "minorias sexuais" e os grupos ditos defensores dos valores tradicionais perpetua um ciclo de preconceito e intolerância que permeia a sociedade moderna. O próprio conceito de tolerância carrega um peso pejorativo que não favorece o convívio pacífico.

A multiplicidade sexual é sentida de forma intuitiva, tornando sem sentido falar-se em minorias sexuais, quando não há uma inferioridade numérica, mas sim uma maioria absoluta de formas distintas de sentir e expressar a sexualidade. Aparentemente, nenhum dos sujeitos atuais parece promover formas efetivas de combater essa forma binária e opressora de pensar. Se é que pode ser combatida.

Nesse contexto, foge aos olhos a questão primordial: o que deve ser pleiteado? A garantia de direitos? O combate ao preconceito?

De acordo com Louro (2013, p. 28):

O grande desafio não é apenas assumir que as posições de gênero e sexuais se multiplicaram e, então, que é impossível lidar com elas apoiadas em esquemas binários; mas também admitir que as fronteiras vêm sendo constantemente atravessadas e - o que é ainda mais complicado - que o lugar social no qual alguns sujeitos vivem é exatamente a fronteira.

O sujeito homossexual foi uma invenção moderna, que remonta ao século XIX. É certo que indivíduos do mesmo sexo mantiveram relações sexuais mesmo entre as civilizações mais antigas. Mas a homossexualidade não configurava uma condição inerente ao indivíduo, e sim uma atividade a que todos estariam sujeitos, e assim, por consequência, poderiam deixar de praticá-la.

O conceito de homossexual tomou forma a partir da segunda metade do século XIX, quando "a prática passava a definir um tipo especial de sujeito que viria a ser assim marcado e reconhecido" (LOURO, 2013, p. 29).

As instituições que regulavam a homossexualidade atribuíam sentidos distintos à prática e aos seus sujeitos. De forma geral, os discursos centravam-se na moral e em uma ética construída socialmente. "Enquanto alguns assinalam o caráter desviante, a anormalidade ou a inferioridade do homossexual, outros proclamam sua normalidade e naturalidade" (LOURO, 2013, p. 30). Mas concordam ao tornar o sujeito homossexual um tipo especial de indivíduo, que difere em essência dos outros.

Por volta dos anos finais da década de 1970, já se falava em uma identidade homossexual. Conforme se politizaram e com grande influência de correntes de pensamento exportadas de outros países onde o debate já se instalara, os grupos militantes proclamavam guetos e uma cultura gay e lésbica. Em pouco tempo, a ideia de uma comunidade homossexual era difundida e suas demandas precisavam ser ouvidas. Esse modelo pode ser chamado "étnico", ou seja, modelo no qual os sujeitos homossexuais representavam "um grupo minoritário, igual, mas diferente" (SPARGO, 1999, p. 29), se almejavam direitos e visibilidade.

A comunidade gay passou a se apropriar de aspectos culturais que passaram a compor suas fronteiras. Ao assumir a sua identidade dentro da ordem social e buscar a equidade de direitos entre seus sujeitos, a militância homossexual assumiu também um status de instituição social com poder regulatório e disciplinador. Suas experiências seriam seguidas e reproduzidas. "Ao afirmar uma posição de sujeito, supõe, necessariamente, o estabelecimento de seus contornos, seus limites, suas possibilidade e restrições" (LOURO, 2013, p. 34).

Essa identidade constituída, apesar de carregar uma essência positiva, por promover o empoderamento e um caráter emancipatório, pode ser questionada:

Como a História da sexualidade de Foucault havia mostrado, tal escolha do objeto nem sempre tinha se constituído a base para uma identidade e, como muitas vozes discordantes sugeriam, esse 
não era, inevitavelmente, o fator crucial na percepção de toda e qualquer pessoa sobre sua sexualidade. Esse modelo fazia, efetivamente, com que os bissexuais parecessem ter uma identidade menos segura ou menos desenvolvida (assim como os modelos essencialistas de gênero fazem dos transexuais sujeitos incompletos), e excluía grupos que definiam sua sexualidade através de atividades e prazeres mais do que através das preferências de gênero, tais como os/as sadomasoquistas. (SPARGO, 1999, p. 34)

A construção dessa identidade nos anos 1970 seguia um "caráter unificador e assimilacionista, buscando a aceitação e a integração dos/das homossexuais no sistema social" (LOURO, 2013, p. 34-35). O movimento, no entanto, ao afirmar e promover a identidade homossexual, não ponderava as tensões dentro da própria comunidade. Apesar de revolucionário em dados pontos, o movimento ainda era fortemente influenciado por uma sociedade patriarcal e por costumes convencionais em que o masculino era, e ainda é, privilegiado. As lésbicas, os bissexuais e os transexuais não podiam ser representados por essa identidade, majoritariamente promovida por homens gays. Mesmo a representatividade entre os homossexuais masculinos não ocorre de forma absoluta.

Mesmo ao defender a homossexualidade como natural, não se deixa de lado o aspecto binário da relação, em contraposição à heterossexualidade. Esta última assume papel de referência, deixando, portanto, a homossexualidade na fronteira que define a norma. "Permanece intocado o binarismo heterossexual/ homossexual como a referência mestra para a construção do eu, do conhecimento sexual e das instituições sociais" (SEIDMAN, 1995, p. 126).

O aparecimento de casos emblemáticos de pessoas com Aids (Acquired Immune Deficiency Syndrome, ou Síndrome da Imunodeficiência Adquirida) e a rápida disseminação do vírus do HIV (Human Immunodeficiency Virus, ou Vírus da Imunodeficiência Humana) levou a disputa a um novo patamar. Inicialmente, e pejorativamente, difundida como "câncer gay", a Aids renovou a homofobia latente que sempre esteve presente na sociedade moderna, dando novo ânimo aos ataques de intolerância e ao estigma.

Nesse ponto, já era possível perceber di- versas alianças e movimentos distintos com propostas complementares e mais contextualizadas.

Em termos globais, multiplicavam-se os movimentos e os seus propósitos: alguns grupos homossexuais permanecem lutando por reconhecimento e por legitimação, buscando sua inclusão, em termos igualitários, ao conjunto da sociedade; outros estão preocupados em desafiar as fronteiras tradicionais de gênero e sexuais, pondo em xeque as dicotomias masculino/feminino, homem/mulher, heterossexual/homossexual; e ainda outros não se contentam em atravessar as divisões, mas decidem viver a ambiguidade da própria fronteira. (LOURO, 2013, p. 38)

Com a crise das identidades, novas teorias surgiam, que por sua vez alimentavam novos movimentos, provocando efeitos em diversos segmentos do movimento homossexual.

A agenda teórica moveu-se da análise das desigualdades e das relações de poder entre categorias sociais relativamente dadas ou fixas (homens e mulheres, gays e heterossexuais) para o questionamento das próprias categorias - sua fixidez, separação ou limites - e para ver o jogo do poder ao redor delas como menos binário e menos unidimensional. (EPSTEIN, JOHNSON, 1998, p. 37-38)

Nesse contexto pós-identitário, a teoria queer tenta completar lacunas nas políticas e nas teorias sociais.

O queer representa o escárnio e o deboche de forma irônica. O termo é parte do rol de insultos utilizado por grupos homofóbicos para designar homens e mulheres homossexuais, ou aqueles que destoam de normas de gênero ou sexuais construídas socialmente. 0 queer promove a subversão ao pensar a cultura sem limitar-se a novos padrões alternativos.

Seu alvo mais imediato de oposição é, certamente, a heteronormatividade compulsória da sociedade; mas não escaparia de sua crítica a normalização e a estabilidade propostas pela política de identidade do movimento homossexual dominante. Queer representa claramente a diferença que não quer ser assimilada ou tolerada, e, portanto, sua forma de 
ação é muito mais transgressiva e perturbadora. (LOURO, 2013, p. 39)

O momento histórico que permitiu o aparecimento dos ideais queer não se limita aos objetos de políticas pontuais ou da teorização gay e lésbica. Diversos fatores interdependentes desencadearam processo de análise da vida social sob o olhar queer.

O queer encontra lugar em uma política e em uma teoria pós-identitária, já que "o foco sai das identidades para a cultura, paras as estruturas linguísticas e discursivas e para seus contextos institucionais" (LOURO, 2013, p. 62).

As normas têm "caráter perfomativo, isto é, têm poder continuado e repetido de produzir aquilo que nomeiam e, sendo assim, elas repetem e reiteram constantemente as normas dos gêneros na óptica heterossexual" (LOURO, 2013, p. 45).

Nesse contexto uma política pós-identitária conceberia mais do que uma forma alternativa de perceber a sexualidade, mas sim uma possibilidade de mudança epistemológica que promova um novo paradigma por meio da desconstrução do binarismo.

Uma abordagem desconstrutiva permitiria compreender a heterossexualidade e a homossexualidade como interdependentes, como mutuamente necessárias e como integrantes de um mesmo quadro de referências. A afirmação da identidade implica sempre a demarcação e a negação do seu oposto, que é construído como sua diferença. Esse "outro" permanece, contudo, indispensável. A identidade negada é constitutiva do sujeito, fornece-lhe o limite e a coerência e, ao mesmo tempo, assombra-o com a instabilidade. Numa óptica desconstrutiva, seria demonstrada a mútua implicação/ constituição dos opostos e se passaria a questionar os processos pelos quais uma forma de sexualidade (a heterossexualidade) acabou por se tornar a norma, ou mais do que isso, passou a ser concebida como "natural". (LOURO, 2013, p. 47)

\section{Uma pedagogia queer}

Os espaços formais de educação, as escolas modernas, compreendem uma das instituições mais facilmente subvertidas à norma e à regulação. A escola reflete a postura da sociedade que a cerca e é regida por suas regras e concepções. Paradoxalmente, a instância que tem a competência de promover a reflexão e o senso crítico, comumente, torna-se espaço de ajustamento e opressão.

Os educadores apontam a presença do conservadorismo e de visões preconceituosas como empecilhos para uma mudança significativa. É importante ressaltar que "dar de ombros e deixar de ter uma posição de intervenção ativa na transformação das ideias conservadoras é o mesmo que as aceitar" (MISKOLCI, 2010, p. 86). De fato, a escola como instituição contemporânea não poderia ser menos queer.

Nesse ponto, são justas as inquietações levantadas por Louro (2013, p. 48):

Como um movimento que remete ao estranho e ao excêntrico pode articular-se com a educação, tradicionalmente o espaço da normalização e do ajustamento? Como uma teoria não propositiva pode "falar" a um campo que vive de projetos e de programas, de intenções, objetivos e planos de ação? Qual é o espaço, nesse campo usualmente voltado ao disciplinamento e à regra, para a transgressão e para a contestação? Como romper com binarismos e pensar a sexualidade, os gêneros e os corpos de uma forma plural, múltipla e cambiante? Como traduzir a teoria queer para a prática pedagógica?

A teoria queer permite uma revolução epistemológica no "pensar o sujeito" ao exaltar as fronteiras do ser como sua própria essência e não mais como uma barreira que delimita e aprisiona. As identidades sexuais e de gêneros são experimentadas e apreendidas livres de estereótipos e ganham uma fluidez que contempla toda a multiplicidade do ser. De acordo com Tomaz Tadeu Silva(2005, p. 107), o queer compreende:

[...] uma atitude epistemológica que não restringe à identidade e ao conhecimento sexuais, mas que se estende ao conhecimento e à identidade de modo geral. Pensar queer significa questionar, problematizar, contestar todas as formas bem-comportadas de conhecimento e identidade. A epistemologia queer é, neste sentido, perversa, subversiva, impertinente, irreverente, profana, desrespeitosa. 
A teoria queer traz visões divergentes de conceitos que não são contemplados no currículo formal em qualquer versão. Os estudos que promovem a diversidade e a tolerância na escola, além de insipientes, não são desenvolvidos de forma concreta e contextualizada, e ainda carregam vícios de uma sociedade marcada pelo patriarcado e pela heteronormatividade.

A postura queer, apesar de provocativa e desestabilizadora, encontra-se comprometida com o empoderamento do marginalizado e com a desconstrução de estereótipos e papéis normatizadores, qualidades essenciais à prática de sala de aula.

Essa desconstrução ocorre por um processo que prioriza as circunstâncias que desencadeiam as diferenças, ou seja, entendendo como as diferenças são produzidas socialmente e as relações de poderes embutidas nessas categorias. Da mesma forma, o queer promove a instabilidade da identidade desvelando sua precariedade.

Ao se dirigir para os processos que produzem as diferenças, o currículo passaria a exigir que se prestasse atenção ao jogo político aí implicado: em vez de meramente contemplar uma sociedade plural, seria imprescindível dar-se conta das disputas, das negociações e dos conflitos constituídos das posições que os sujeitos ocupam. (LOURO, 2013, p. 50)

A pedagogia queer encontra-se, propositalmente, inacabada, não trazendo consigo fórmulas ou soluções. Não tem a pretensão de encerrar o debate, mas de desestabilizar e de desnaturalizar as estruturas que produzem as divergências. Tenta desestruturar os binarismos, mostrando suas contradições e generalismos.

Efetivamente, os contornos de uma pedagogia ou de um currículo queer não são os usuais: faltam-lhes as proposições e os objetivos definidos, as indicações precisas do modo de agir, as sugestões sobre as formas adequadas para "conduzir" os/as estudantes, a determinação do que "transmitir". A teoria que lhes serve de referência é desconcertante e provocativa. Tal como os sujeitos de que fala, a teoria queer é, ao mesmo tempo, perturbadora, estranha e fascinante. Por tudo isso, ela parece arriscada. E talvez seja mesmo... mas, seguramente, ela faz pensar. (LOURO, 2013, p. 54)

\section{Referências}

BEAUVOIR, S. D. O segundo sexo. v. 2. Rio de Janeiro: Nova Fronteira, 1980.

BUTLER, J. Bodies that matter: on the discurse limits of sex. Nova York: Routledge, 1993.

BUTLER, J. Problemas de gênero: feminismo e subversão da identidade. Rio de Janeiro: Civilização Brasileira, 2010.

EPSTEIN, D.; JOHNSON, R. Schooling sexualities. Buckinghan: Open University Press, 1998.

LOURO, G. L. Um corpo estranho: ensaios sobre sexualidade e teoria queer. 2. ed. Belo Horizonte: Autêntica, 2013.

MISKOLCI, R. Sexualidade e orientação sexual. In: MISKOLCI, R. Marcas da diferença no ensino escolar. São Carlos: EdUFSCar, 2010. p. 75-111.

SALIH, S. Judith Butler e a teoria queer. Tradução de Guacira Lopes Louro. Belo Horizonte: Autêntica, 2013.

SEEDGWICK, E. Tendencies. Londres: Routledge, 1994.

SEIDMAN, S. Desconstructing queer theory or the under-theorization of the social and the ethical. In: NICHOLSON, L.; SEIDMAN, S. Social postmodernism: beyond identify politics. Cambridge: Cambridge University Press, 1995. p. 116-141.

SILVA, T. T. Documentos de identidade: uma introdução às teorias do currículo. 2. ed. Belo Horizonte: Autêntica, 2005.

SPARGO, T. Foucalt and queer theory. Nova York: Totem Books, 1999. 
